\title{
Theoretical Conceptions on Macrostructures of Bar Soap and Study of Adsorption of Sodium Salts of Fatty Acids on the Fabrics
}

\author{
S.S. Saidvaliev*, K.Kh. Majidov and M.M. Mamatov \\ Bukhara Engineering-Technological Institute, 15, K. Murtazaevstreet, \\ Bukhara city, Uzbekistan \\ *Corresponding author
}

A B S T R A C T

\section{Keywords}

Soap mass, Structure formation, Fatty acids,

Temperature,

Humidity,

Macrostructure,

Salable condition,

Crystals, Adsorption,

Fabric, Layer,

Thickness, Washing

properties, Structure,

Hydrocarbon radical

Article Info

Accepted:

22 June 2020

Available Online:

10 July 2020
Using existing scientific propositions as a basis, the structure of bar commercial soap is made. It has been stated that the macrostructure of commercial soap takes the form of hexagonal prismatic cells, which are the most energetically beneficial form of full-wall crystallization structures of the system. Maximum mechanical strength is achieved within concrete time after forming the soap mass into the cake soap form. It was defined that the structure and properties of each fabric layer takes intermediate position between the previous and subsequent layers. Transition to three-phase system is achieved at thickness of remaining contaminants of co-resistant with length of hydrocarbon part of anion.

\section{Introduction}

At present, the features of the composition and structure of the salable conditions of bar soaps have not been sufficiently studied. The information has generally known nature, and is not correlated with the practical tasks of soap production (Arutyunyan, 1998; Abramzon, 1985).

Existing conceptions are based on the study of properties of bar soaps consisting of low- concentration sodium salts of fatty acids (Pochernikov, 1983), and is applicable to highly-concentration real systems consisting of mixtures of differing each other salts. The practical use of soap requires the establishment and determination of its detergent abilities when processing different kinds of fabrics. Thermodynamic and quasichemical models of detergent action of surfactants are practically not correlated with real processes. The number of fundamental questions of theory and practice do not have a 
clear explanation. In particular, one of the fundamental questions about the quantitative assessment of the adsorption of sodium salts of fatty acids under practical conditions at different stages of the washing process is the subject of ongoing discussions. Examination and determination of adsorption properties of sodium salts of fatty acids of bar soap varieties on fabrics is an urgent issue.

Purpose of the work is aimed at summarizing the theoretical concepts of macrostructures of bar soap and at studying adsorption of sodium salts of fatty acids on fabrics.

\section{Materials and Methods}

Microcopy method has established the form of structure formation of the soap base of bar soap (Arutyunyan, 1998; Abramzon, 1985). The transformation of vesicles into a cellularreticular structure of crystals of sodium salts of fatty acids was visually established (Pochernikov, 1983; Tanford, 1979). To solve the studied problems methods of quantitative evaluation of adsorption of sodium salts of fatty acids at washing process stages of solid soaps in treatment of different types of fabrics were used (Pochernikov, 2009; Saidvaliev, et.al, 2010). Density of adsorption layer of examined fabric is selected as treatment objects (Saidvaliev, et.al, 2010).

\section{Results and Discussion}

It has been experimentally established (Saidvaliev et al., 2010; Sergeev, 1975) that the final structuring form of soap base of bar soap in the temperature range $95-70{ }^{\circ} \mathrm{C}$ is characterized by the system of hexagonal packed cylindrical vesicles (Fig. 1) of various diameters, containing solution of fatty acid salts as in internal cavities of vesicles, and in intervesicular space.
It is obvious that technological lowering of temperature and residual humidity will lead to a change in the form of structuring of the entire system.

At the temperature below $55{ }^{\circ} \mathrm{C}$ and residual moisture content of less than $20 \%$, contact surfaces are likely to merge at the contact points of cylindrical vesicles, and, at the same time as the vesicles transform into a cellularreticular structure, crystallization of sodium salts continues in its walls. Then the microstructure of commercial soap takes the form of hexagonal prismatic cells, which are the most energetically favorable form of cavity structures, which is shown in Fig. 1.

To develop a practical scheme of the initial stage of the washing process - adsorption, the study method has been used, which reflects real processes and is pre-weighed contaminated according to GOST 22567.15 "Synthetic detergents. Method for determining the ability" (Sergeev, 1975; Buchstab et al., 1988), the fabric was treated for 3-6 sec with solution of sodium salts of fatty acids of $1 \%$ concentration, followed by drying to constant weight at a temperature of $40^{\circ} \mathrm{C}$. The results of the study are in table 1 .

As can be seen from the data presented, on both sides of the tested fabric samples with total area of $2 \mathrm{~S}=1.17 \cdot 10^{-2} \mathrm{~m}^{2}$ was adsorbed $\Delta \mathrm{M}=1.35 \cdot 10^{-5} \mathrm{~kg}$ of soap anions (molecules), which is about $1.2 \cdot 10^{-3} \mathrm{~kg}$ of soap per square meter of contaminated surface. Two assumptions were used in the work. The first assumption - the thickness of the adsorption layer is equal to the length of the hydrocarbon radical of the longest molecule (in this case stearic acid) and is about $1=2.6 \cdot 10^{-9} \mathrm{~m}$, the second - the density of the adsorption layer is equal to the density of the bar soap and can be $\gamma=1.0 \cdot 10^{3} \mathrm{~kg} / \mathrm{m}^{3}$. Then the number of adsorption layers $\mathrm{K}$ reaches the values of equal $4.6 \cdot 10^{2}$ : 


$$
K=\frac{\Delta M}{\gamma \cdot 2 l}=\frac{1,2 \cdot 10^{-3}}{1 \cdot 10^{3} \cdot 2,6 \cdot 10^{-9}}=4,6 \cdot 10^{2}
$$

Therefore, considering the experimental error and the assumptions made, it can be counted that the surface layers of anions on the contaminated surface, because of adsorption, consist of more than one monolayer, and the total number of adsorption layers can be two or more orders of magnitude.

When applying soap onto the surface of contaminated fabric by mechanical method performed by three-fold movement of the bar on one side of the fabric sample with area equal to $5.85 \cdot 10^{-3} \mathrm{~m}^{-2}$, the average value of weight gain of dried fabric $\Delta \mathrm{M}$ was $1.17 \cdot 10^{-4}$ $\mathrm{kg}$. Consequently, we can assume that 2.0 $10^{-}$ ${ }^{2} \mathrm{~kg}$ of soap anions (molecules) wereadsorbed on a surface of $1 \mathrm{~m}$ :

$$
\frac{1 \cdot \mathrm{m}^{3} \cdot 1,17 \cdot 10^{-4} \mathrm{~kg}}{5,85 \cdot 10^{-3} \mathrm{~m}^{2}}=2,0 \cdot 10^{-2} \mathrm{~kg}
$$

Then, assuming in this case the bilayer structure of the adsorption layers, the thickness of which is equal to twice the length of the hydrocarbon radical of the longest molecule (stearic acid) and is $2 l=5.8 \cdot 10^{-9} \mathrm{~m}$, the number of adsorption layers $\mathrm{K}$ can increase significantly, and reach values equal $3.5 \cdot 10^{3}$ :

$$
K=\frac{\Delta M}{\gamma \cdot 2 l}=\frac{2,0 \cdot 10^{-2}}{1 \cdot 10^{3} \cdot 5,8 \cdot 10^{-9}}=3,5 \cdot 10^{3}
$$

It is remarkable that the quantity of adsorptive layers, apparently from calculations, is not function (almost does not depend on their thickness).
In general, the diagram of the adsorption layers during the initial period of the washing process is shown in Fig.2

The driving force behind the start of the adsorption process is the concentration difference

$\Delta \mathrm{C}=\mathrm{C}_{\mathrm{M}}-\mathrm{C}_{0}$

whereC $_{\mathrm{M}}$-micellar wash solution with concentration well above $\mathrm{CMC}$, and $\mathrm{C}_{0}$ - the concentration of anions on the surface of the pollution is equal to 0 . As a result, in the boundary layer there is dissociation of washing solution micelles and free anions adsorbing on the contamination surface form a monolayer, hydrocarbon radicals of which are immersed in the contamination |2|. Solution micelles are suppliers of anions and provide adsorption to complete saturation on the top layer of contamination. The structure of the monolayer serves as a prototype for further structuring of the system and its properties are determined by both the nature of the contaminants and the lengths of the hydrocarbon radicals of the anions and the degree of their unsaturation. Obviously, the second adsorption layer $|4|$ is a bilayer representing micelle of lamellate structure. Its structure is formed under the simultaneous influence of the monolayer and micelles of the initial solution, which determines the intermediate value of its properties. Formation of the third and subsequent layers proceeds by the same mechanism. As a result, a system of bilayers separated by thin layers of the aqueous phase $|3|$ is formed.

Obviously, the structure and properties of each layer are intermediate between the previous and the next layer.

Consequently, the structure of the second bilayer will be close to the structure of the monolayer, and the upper layer of the 
adsorption system will correspond to the structure and properties of the micelles of the original solution. The total thickness of adsorption layers $\mathrm{H}$ with successively varying structure and properties can be about $10^{-5}$ $10^{-6} \mathrm{~m}$.

It is important to note that under experimental conditions the hydrocarbon radicals of the monolayer anions, which are $2.6 \cdot 10^{-10} \mathrm{~m}$ long, do not reach the surface of the fabric |1|, since the total thickness of the contaminants is about $10^{-6}-10^{-5} \mathrm{~m}$.

Then the washing system under experimental conditions can be presented in the form of a two-phase system: the washing solution contaminants, and the washing process in the initial stage - as layer-by-layer separation of contaminant parts from their common mass.

Transition to three-phase system: washing solution - contamination - fabric is achieved at thickness of remaining contaminants comparable to length of hydrocarbon part of anion. Moreover, it is at this stage that the removal of contamination directly from the surface of the fabric begins.

Therefore, in the conditions of the experiments, the initial stage of the real washing process can be represented by the following scheme: multilayer adsorption $\rightarrow$ layer-by-layer removal of contaminants $\rightarrow$ the beginning of the removal of pollution from the surface being cleaned.

Table.1 The mass of soap anions adsorbed on the contaminated surface of the fabric

\begin{tabular}{|c|c|c|c|c|c|c|c|}
\hline \multicolumn{2}{|c|}{$\begin{array}{c}\text { Parameters of } \\
\text { solution }\end{array}$} & \multirow{2}{*}{$\begin{array}{c}\text { Fabric } \\
\text { treatment } \\
\text { time with } \\
\text { solution, } \\
\text { sec }\end{array}$} & \multirow{2}{*}{$\begin{array}{c}\text { Dimensio } \\
\text { ns of } \\
\text { fabric } \\
\text { sample, } \\
\text { mm }\end{array}$} & \multirow{2}{*}{$\begin{array}{c}\text { Mass of } \\
\text { the } \\
\text { initial } \\
\text { sample } \\
\left(M_{\mathrm{T}}\right), \mathrm{g}\end{array}$} & \multirow{2}{*}{$\begin{array}{c}\text { Drying } \\
\text { temper } \\
\text { ature, } \\
{ }^{\circ} \mathrm{C}\end{array}$} & \multirow{2}{*}{$\begin{array}{c}\text { Mass of } \\
\text { the dried } \\
\text { sample } \\
\left(\mathbf{M}_{2}\right), \mathrm{g}\end{array}$} & \multirow{2}{*}{$\begin{array}{c}\Delta \mathbf{M} \\
(\mathbf{M} 2- \\
\left.\mathbf{M}_{1}\right), \mathbf{g}\end{array}$} \\
\hline $\begin{array}{c}\text { Concent } \\
\text { ration, } \\
\%\end{array}$ & $\begin{array}{c}\text { Temper } \\
\text { ature, } \\
{ }^{\circ} \mathrm{C}\end{array}$ & & & & & & \\
\hline 1.0 & 40.0 & 3 & $65.0 \times 90.0$ & 0.9490 & 40.0 & 0.9355 & 0.0133 \\
\hline 1.0 & 40.0 & 4 & $65.0 \times 90.0$ & 0.9392 & 40.0 & 0.9258 & 0.0134 \\
\hline 1.0 & 40.0 & 5 & $65.0 \times 90.0$ & 0.9574 & 40.0 & 0.9439 & 0.0135 \\
\hline 1.0 & 40.0 & 6 & $65.0 \times 90.0$ & 0.9398 & 40.0 & 0.9262 & 0.0136 \\
\hline
\end{tabular}

Table.2 The number of adsorption layers of soap anions (molecules) on the surface of a clean fabric

\begin{tabular}{|c|c|c|c|c|c|c|c|}
\hline $\begin{array}{l}\text { The time of } \\
\text { processing the } \\
\text { fabric with } \\
\text { solution, sec }\end{array}$ & $\begin{array}{l}\text { The mass of } \\
\text { the initial } \\
\text { sample of } \\
\text { fabric }\left(M_{1}\right), g\end{array}$ & $\begin{array}{l}\text { The mass of the } \\
\text { processed } \\
\text { fabric sample } \\
\left(\mathrm{M}_{2}\right), \mathrm{g}\end{array}$ & $\begin{array}{c}\Delta \mathbf{M} \\
\left(\mathbf{M}_{2}-\mathbf{M}_{1}\right) \\
\Gamma\end{array}$ & $\begin{array}{l}\text { The mass of the } \\
\text { fabric sample after } \\
\text { rinsing }\left(\mathrm{M}_{3}\right), g\end{array}$ & $\begin{array}{c}\Delta \mathbf{M}_{1} \\
\left(\mathbf{M}_{2}-\mathbf{M}_{1}\right) \\
\mathbf{g}\end{array}$ & $\underset{10^{-4} \mathrm{~kg}}{\Delta \mathrm{M}_{1}}$ & K \\
\hline 3 & 0.8930 & 0.9128 & 0.0198 & 0.8950 & 0.0020 & 1.7 & 29 \\
\hline 4 & 0.8743 & 0.8936 & 0.0193 & 0.8769 & 0.0026 & 2.0 & 34 \\
\hline 5 & 0.8837 & 0.9032 & 0.0195 & 0.8868 & 0.0031 & 2.6 & 45 \\
\hline 6 & 0.8692 & 0.8883 & 0.0191 & 0.8733 & 0.0041 & 3.5 & 60 \\
\hline
\end{tabular}


Fig.1 Structure of bar commercial soap: 1 - crystal framework with hexagonal cell, 2 - solution of fatty acid salts in the cell

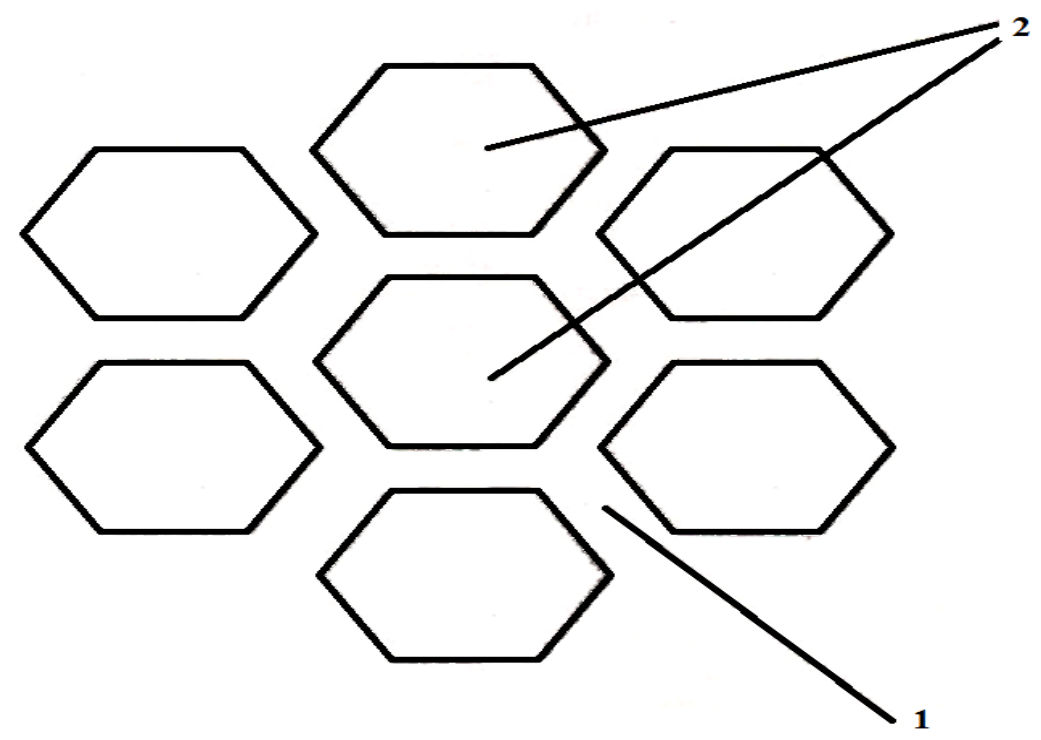

Fig.2 Diagram of adsorption layers during initial stage of washing process:

1- surface of the fabric, 2- contamination film, 3- aqueous phase, 4- adsorption layer. $\mathrm{H}$ - total thickness of the adsorption layers

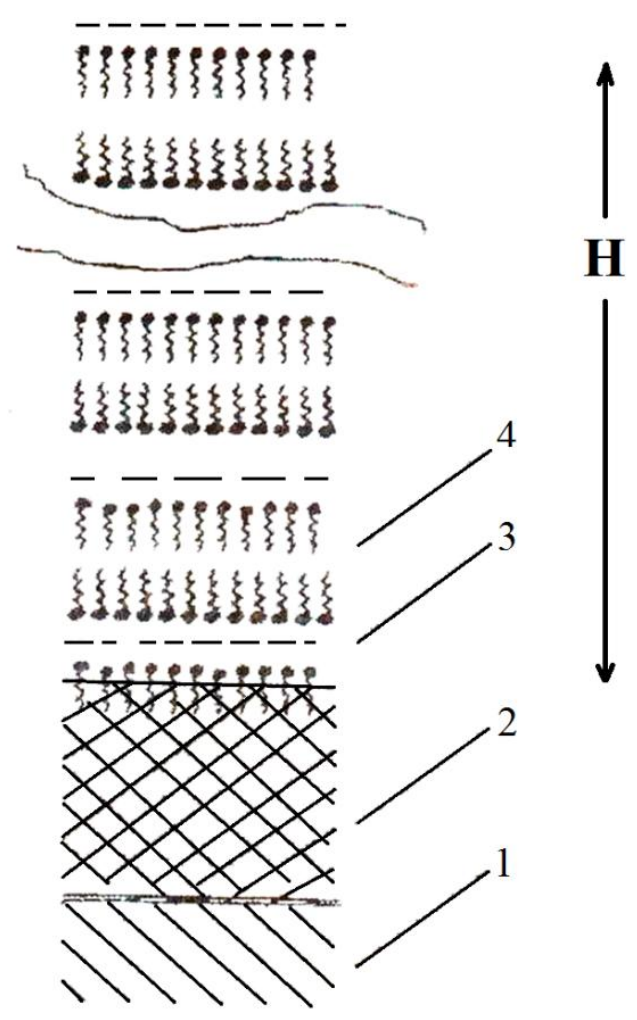


To study the hydrophobization of the surface of the cleaned fabric, an assumption was made about the complete removal of contamination from the test fabric sample during the washing process and subsequent experiments were carried out with samples of uncontaminated fabric. The research method consisted in the fact that a pre-weighed sample of uncontaminated fabric was treated for 3-6 sec a solution of sodium salts of fatty acids of $1 \%$ concentration, followed by drying to a constant weight at a temperature of $40^{\circ}$ C. Then the fabric was rinsed in the modes corresponding to GOST 22567.15 "Synthetic detergents. Method for determining the washing ability" and dried to constant weight at a temperature of $40^{\circ} \mathrm{C}$. The results of the study are presented in table 2 .

From the data presented in Table 2, it can be seen that $11.7-3.5 \cdot 10^{-4} \mathrm{~kg} / \mathrm{m}^{2}$ of soap anions (molecules) that form about 29-60 adsorption layers remain on the surface of the washed fabric after rinsing.

It follows that multilayer adsorption of anions is a fundamental action of the entire washing process - from its initial stage to the final removal of contamination with maximum dilution of the washing solution in rinse mode.

It is concluded that consideration of physicalchemical model of bar soap structure has established three-dimensional solid-like system consisting of mixed crystals of sodium salts of fatty acids.

\section{References}

Abramzon A.A., Yakovlev V.D., Merzlikina Z.K., Tolkachev S.P. Some aspects of the mechanism of the washing action of surface-active materials // JPKh. 1985, p. 1018-1023.

Arutyunyan N.S. Fat processing technology. M.: Pishepromizdat, 1998.

Buchstab Z.I., Melnik A.P., Kovalev V.M. Technology of synthetic detergents. M .: Legpromizdat, 1988.

Manual on technology of production and processing of vegetable oils and fats / Ed. A.G. Sergeev. L.: VNIIZH, 1975, vol. 4.

Pochernikov V.I. To the question of structural changes in industrial systems consisting of sodium salts of fatty acids. - M.: Vestnik magazine 2009 No. 1 p. 17-19

Pochernikov V.I., Leshchenko N.F. On the issue of obtaining a new detergent. - M.: AgroNIITEIPP, 1987. Issue 5, p. 20.

Rosen M., Liu L. Surface Activity and Premicellar Aggregation of Some Novee Digyatemary Gemini Surfactants // JAOCS. 1996. Vol.73. No. 7. p.885890.

Saidvaliev, S.S., A.M. Rakhimov, M.N. Rakhimov, K.Kh. Majidov Developments to create new types of toilet soaps and improve their quality // Journal "Chemistry and chemical technology", - 2010, No. 30, p. 2.

Saidvaliev, S.S., M.N. Rakhimov, K.Kh. Majidov, Sh. Shomuratov Toilet dressing on the basis of shavings of raw material. Collection of works of republican scientific-technical conference. Tashkent, Tashkent chemical-technological institute. 2010, p. 141-143.

Tanford Ch. The Hydrophobic Effect: Formation of Micelles and Biological Membranes. 2 ${ }^{\text {nd }}$ Ed. New York: John Wiley, 1979. p. 241. 


\section{How to cite this article:}

Saidvaliev, S.S., K.Kh. Majidov and Mamatov, M.M. 2020. Theoretical Conceptions on Macrostructures of Bar Soap and Study of Adsorption of Sodium Salts of Fatty Acids on the Fabrics. Int.J.Curr.Microbiol.App.Sci. 9(07): 2931-2937. doi: https://doi.org/10.20546/ijcmas.2020.907.345 